\title{
LA VIDA ENTRE LA SOBERANÍA, LA BIOPOLÍTICA Y EL ARTE*
}

\author{
WiLLIAM CERÓN**
}

Fecha de recepción: 3 de noviembre de 2010 • Fecha de aceptación: 9 de diciembre de 2010

\section{Resumen}

El artículo defiende la tesis de que nuestra vida está mejor gobernada por uno mismo que por el soberano. Alcanzar un modo de ser para hacer de la vida una obra de arte que pueda definirse por el pleno disfrute de sí mismo, o la perfecta soberanía de sí en oposición al poder del soberano y de la Biopolítica, es nuestra tesis a defender.

Palabras clave: soberanía, liberalismo, biopolitica, moral, arte, cuidado de sí.

* El artículo es producto del semillero de investigación Ius-Parrhesía de la Facultad de Derecho de la Universidad Autónoma Latinoamericana-UNAULA.

** Filósofo. Magíster en Estudios Políticos y doctorando en Filosofía de la Universidad Pontificia Bolivariana. Docente investigador de la Universidad Autónoma LatinoamericanaUNAULA. Autor del libro La Filosofía Política en Michel Foucault: una obra para repensar la política. Universidad Autónoma Latinoamericana-UNAULA. Coautor de los libros Posontología y posmetafísica en el siglo XXI, Universidad Pontificia Bolivariana; Pragmatismo, posmetafísica y religión, Universidad Pontificia Bolivariana; Escenarios de reflexión: las ciencias sociales y humanas a debate, Universidad Nacional. Dos han sido sus líneas de investigación: Biopolítica, el poder sobre las poblaciones y Ius-parrhesia, la verdad en el Derecho. Dirección electrónica: magisterpolitica@yahoo.es 


\section{Abstract}

The article argues that our lives are better governed by oneself than by the soberano. Alcanzar a way to make a work of art that can define the full enjoyment of himself, or perfect sovereignty if in opposition to the power of the sovereign and the biopolitics of life is our thesis to defend.

Keywords: sovereignty, liberalism, biopolitica, morals, art, taken care of if. 
La vida entre la soberanía, la biopolítica y el arte

Las guerras ya no se hacen en nombre del soberano al que hay que defender; se hacen en nombre de la existencia de todos; se educa a las poblaciones enteras para que se maten mutuamente en nombre de la necesidad que tienen de vivir.

Foucault, 1978

\section{INTRODUCCIÓN}

Este acto de escribir implica para nosotros cambiar la manera de pensar sobre el arte, puesto que cuando hablamos de él nos imaginamos, quizás, una pintura de Van Gogh, la Mona Lisa de Leonardo da Vinci, las esculturas de Fernando Botero, las catedrales góticas, la Novena sinfonía de Beethoven, o simplemente nos remitimos a las obras inmortales de Platón, Nietzsche, Heidegger. Los expertos de arte responden a nuestras inquietudes: ¿Qué es el arte y qué no es?, ¿Qué placer produce en nosotros?, ¿Cómo diferenciar el arte de la técnica, la artesanía y el folclor? Nuestras reflexiones no versan sobre estas preguntas que les dejamos a los artistas. Antes bien, se proponen pistas embrionarias sobre cómo hacer de la vida una obra de arte. Para ello tomamos prestada la tesis de Michel Foucault, quien poco antes de su muerte escribió:

Lo que me sorprende es el hecho de que en nuestra sociedad el arte se haya convertido en algo que no concierne más que a los objetos, y no a los individuos ni a la vida. Que el arte es una especialidad hecha solo por los expertos que son los artistas, pero ¿Por qué no podría cada uno hacer de su vida una obra de arte? ¿Por qué esta lámpara, esta casa, sería un objeto de arte y no mi vida? (Foucault, 199: 193).

Así, pues, nuestras indagaciones apuntan a gobernar la propia vida para darle una forma que sea la más bella posible, es decir, conservar superioridad sobre nuestros apetitos y placeres, mantener los sentidos en un estado de tranquilidad, permanecer libre de toda esclavitud interior y exterior, alcanzar un modo de ser que pueda definirse por el pleno disfrute de sí mismo, o la perfecta soberanía de sí sobre sí; pero antes de empezar con nuestra reflexión es necesario dar respuesta a estos interrogantes: ¿Qué es la 
vida?, ¿Quién tiene la potestad de hacer morir o dejar vivir?, ¿Quién administra nuestra vida?, ¿Cómo hacer que nosotros mismos seamos los artistas de nuestra existencia?

Pues bien, en cualquiera de sus formas, el poder no creaba vida porque no tenía en sus manos esa capacidad; se limitaba a dejar vivir a los súbditos y animaba a las parejas a procrear, con el auxilio de la religión. Dios es quien puede crear la vida y terminar con ella ${ }^{1}$; los humanos solo pueden destruirla, y en ese momento se crean un nicho en el infierno por dañar la obra divina. Por eso, la especie humana cruzará un umbral ontológico cuando tenga el poder de generar vida donde no existía, es decir, a partir de la materia inerte. Más divinos serán si la vida que crean, además, es inteligente.

Friedrich Nietzsche (1844-1900) fue quizás el primero en oponerse a la tesis creadora de la naturaleza al afirmar que la vida humana es producto del poder que la genera y la destruye, puesto que "Dondequiera que encontrara vida, encontré la voluntad de poder" (Nietzsche, 2000: 573), en tanto que el poder constituía de hecho el medio por el que sucedían todas las cosas: el conocimiento, las formas de discurso, el placer y la vida misma. Es aquí donde se rompe con la tradición y se postula una nueva mirada sobre el mundo y el hombre, no con base en ningún fundamento metafísico sino en la vida misma (voluntad de poder) ${ }^{2}$. Por tal motivo fue Nietzsche el

1 En el Credo de Israel, afirmar que Dios es Creador no significa solamente expresar una convicción teorética, sino también captar el horizonte original del actuar gratuito y misericordioso del Señor en favor del hombre. Él, en efecto, libremente da el ser y la vida a todo lo que existe. El hombre y la mujer, creados a su imagen y semejanza: "Dijo Dios: hagamos al hombre conforme a nuestra semejanza. Que tenga autoridad sobre los peces del mar y sobre las aves del cielo, sobre los animales de campo, las fieras salvajes y los reptiles que se arrastran por el suelo. Y creó Dios al hombre a su imagen. A imagen de Dios lo creó. Macho y hembra los creó. Dios los bendijo, diciéndoles: Sean fecundos y multiplíquense." (Cf. La Biblia latinoamericana, 1995: 8).

2 Qué quiere decir "voluntad" puede experimentarlo en sí mismo cualquiera en cualquier momento: querer es un aspirar a algo. Qué significa "poder" lo sabe cualquiera por la experiencia cotidiana: el ejercicio de la fuerza [Gerwalt].Qué quiere decir, entonces, "voluntad de poder" en su conjunto es tan claro que uno se resiste a dar una explicación especial de este conjunto de palabras. "Voluntad de poder" es, inequívocamente, un tender a la posibilidad de ejercer la fuerza, un tender a la posesión de poder. La "voluntad de poder, expresa, además "un sentimiento de carencia". La voluntad "de no es aún el poder mismo, pues no es aún propiamente tener el poder. El anhelar algo que aún no es, se considera un signo de romanticismo. Pero esta voluntad de poder, en cuanto pulsión de tomar el poder es, 
primer filósofo que afirmó que el poder no es totalidad sino particularidad; es decir, que el poder no es un asunto metafísico e ideológico sino que es una relación permanente entre los seres humanos.

Entonces, el poder sobre la vida para el filósofo alemán no depende de la voluntad del Creador, sino de la voluntad de los hombres que, dotados de cierta fuerza y poder, logran someter a los más débiles. En este sentido el hombre no crea vida, sino que la destruye en virtud del instinto animal que lleva por dentro. Michel Foucault, continúa y amplía la tesis de Nietzsche. Analicemos:

\section{El derecho de soberanía: hacer morir o dejar vivir}

Foucault presenta de forma detallada cómo el soberano en el Medioevo tenía el derecho "de vida y muerte" de "hacer morir o dejar vivir" (Foucault, 1992: 49). Es de anotar que el soberano no gobierna, no dirige la voluntad de los gobernados, menos aún timonea la ciudad. Contrario a ello, ejerce la violencia para hacerse obedecer, su fuerza para desviar, capturar, extraer, aplacar, en definitiva, sustraer al gobernado.

En el siglo XIX apareció otro tipo de crítica de las instituciones políticas, mucho más radical puesto que se trataba de mostrar no solo que el poder real escapaba a las reglas del Derecho, sino que el sistema mismo del Derecho era una manera de ejercer la violencia, de anexarla en provecho de algunos, y de hacer funcionar bajo la apariencia de la ley general, las asimetrías de la injusticia de una dominación. (Foucault, 1978: 108)

El filósofo francés analiza que el poder político construido a partir de un contrato corre el riesgo de terminar en la opresión, porque en cualquier momento el pacto se puede romper y en consecuencia el poder puede ir más allá de sus confines:

al mismo tiempo, el puro afán de violencia. Este tipo de interpretaciones de la "voluntad de poder", en las que se encontrarían romanticismo y maldad, deforman el sentido de la expresión fundamental de la metafísica de Nietzsche; en efecto, cuando éste dice "voluntad de poder”, piensa algo diferente. Cf. (Heidegger, 2009) 
El poder así constituido corre el riesgo de hacerse opresión cuando sobrepasa a sí mismo, es decir, cuando va más allá de los términos del contrato. Poder-contrato con la opresión como límite o más bien, como la superación del límite" (Foucault, 1978: 31).

Un ejemplo claro sucedió en el siglo XVII y a comienzos del siglo XVIII, cuando un individuo cometió un crimen mediante el cual lastimó desde luego a una serie de personas, pero había atentado contra el soberano. Por tal motivo, éste tendrá que ejercer la justicia a través del suplicio. Pero dejemos que el mismo Foucault nos lo cuente:

El suplicio pone en correlación el tipo de perjuicio corporal, la calidad, la intensidad, la duración de los sufrimientos con la gravedad del delito, la persona del delincuente y la categoría de sus víctimas. Existe un código jurídico del dolor; la pena, cuando es supliciante, no cae al azar o de una vez sobre el cuerpo, sino que está calculada de acuerdo con reglas escrupulosas: número de latigazos, emplazamiento del hierro al rojo, duración de la agonía en la hoguera o en la rueda (el tribunal decide si procede estrangular inmediatamente al paciente en vez de dejarlo morir, y al cabo de cuánto tiempo ha de intervenir este gesto de compasión), tipo de mutilación que imponer (mano cortada, labios o lengua taladrados). Todos estos elementos diversos multiplican las penas y se combinan según los tribunales y los delitos: "La poesía de Dante hecha leyes", decía Rossi; un largo saber físico-penal, en todo caso. El suplicio forma, además, parte de un ritual. Es un elemento en la liturgia punitiva, y que responde a dos exigencias. Con relación a la víctima, debe ser señalado: está destinado, ya sea por la cicatriz que deja en el cuerpo, ya por la resonancia que lo acompaña, a volver infame a aquel que es su víctima; el propio suplicio, si bien tiene por función la de "purgar" el delito, no reconcilia; traza en torno o, mejor dicho sobre el cuerpo mismo del condenado unos signos que no deben borrarse; la memoria de los hombres, en todo caso, conservará el recuerdo de la exposición, de la picota, de la tortura y del sufrimiento debidamente comprobados. Y por parte de la justicia que lo impone, el suplicio debe ser resonante, y debe ser comprobado por todos, en cierto modo como su triunfo. El mismo exceso de las violencias infligidas es uno de los elementos de su gloria: el hecho de que el culpable gima y grite bajo los golpes, 
no es un accidente vergonzoso, es el ceremonial mismo de la justicia manifestándose en su fuerza. De ahí, sin duda, esos suplicios que siguen desarrollándose aún después de la muerte, cadáveres quemados, cenizas arrojadas al viento, cuerpos arrastrados sobre zarzos, expuestos al borde de los caminos. La justicia persigue al cuerpo más allá de todo sufrimiento posible. (Foucault, 1999: 40)

Es de mencionar que en las monarquías absolutas, donde el soberano es el artista de la vida de los súbditos, no se da la vigilancia continua ni tampoco las disciplinas, pero sí se aplica el castigo a todo aquel individuo anormal que se atreve a romper el pacto establecido; pero para ilustrar mejor lo comentado, el autor de Vigilar y castigar nos presenta un caso concreto de un suplicio ${ }^{3}$ realizado en el siglo XVII, en el que un joven cometió un parricidio y para hacer justicia se le aplicó la pena corporal ${ }^{4}$, para ser quemado, desmembrado, y consumido por el fuego. Examinemos:

Damiens fue condenado, el 2 de marzo de 1757, a "pública retractación ante la puerta principal de la Iglesia de París adonde debía ser "llevado y conducido en un carreta, desnudo, en camisa, con un hacha de cera encendida de dos libras de peso en la mano" después, "en dicha carreta, a la plaza de Grève, y sobre un cadalso que allí habrá sido levantado [deberán ser] atenaceadas las tetillas, brazos, muslos y pantorrillas, y su mano derecha, asido en ésta el cuchillo con que cometió dicho parricidio, quemado con fuego de azufre, y sobre las partes atenaceadas se le verterá plomo derretido, aceite hirviendo, pez resina ardiente, cera y azufre fundidos juntamente, y a continuación su cuerpo estirado y desmembrado por cuatro caballos y sus miembros y troncos consumidos en el fuego reducidos a ceniza y sus cenizas arrojadas al viento. (Foucault, 1999: 11)

3 Enunciemos algunas características del suplicio que se realizaba en el siglo XVIII. Hacer en primer lugar del culpable el pregonero de su propia condena 2. Proseguir una vez más la escena de la confesión. 3. Exposición del cadáver del condenado en el lugar de su crimen 4. En fin, la lentitud del suplicio, sus peripecias, los gritos y sufrimientos del condenado desempeñan, al término del ritual judicial, el papel de una prueba única. (Foucault: 1999: 49,51)

4 Debemos aclarar que para que una pena sea suplicio, debe producir cierta cantidad de sufrimiento tal que no pueda medirse o jerarquizarse. 
Como vemos, dentro de su figura el soberano ocultaba salvajismo y un mundo de atrocidad para quien atentara contra lo dispuesto legalmente. Este símbolo sociocultural era el encargado de hacer morir en vida a los supliciados imponiendo penas según el delito cometido. El suplicio era un verdadero rito judicial que llevaba a la verdad y un ritual político, pues se hacía público, sin la exposición pública no tendría sentido todo el propósito del mismo pues con su poderosa carga simbólica se representa la lucha entre el delincuente y el prócer. Por medio de esta práctica los inocentes confesaban la comisión de un delito que no cometieron con tal de no seguir con el sufrimiento. No se equivocaba Foucault al afirmar: "Hay culpables con la firmeza suficiente para ocultar un crimen verdadero, otros, inocentes, a quienes la intensidad de los tormentos hace confesar crímenes de los que no son culpables" (Foucault, 1999: 55)

Es necesario recordar que, dependiendo de las pruebas, son las penas, las cuales argumentan cualquier suplicio, penas menos plenas que llevan a penas aflictivas pero no mortales y los adminículos o penas lejanas que suponen una multa o pena no corporal. Digámoslo con Foucault (1999):

Todavía en al siglo XVIII se encontraban regularmente distinciones como éstas: pruebas ciertas, directas o legítimas (los testimonios, por ejemplo); o las pruebas indirectas, conjeturales, artificiales (por argumento) o las pruebas manifiestas o leves, también las pruebas "urgentes o necesarias" que no permiten dudar de la verdad del hecho (son penas plenas). (p. 42)

Admitamos: el poder busca legitimarse como derecho, aunque lo haga en nombre de la justicia y en función del bien común, ello no es más que discurso-poder, es parte de la dinámica de las fuerzas. Frente a esta situación, surgen las preguntas: ¿Qué hace que el poder se sostenga, sea aceptado?, ¿Por qué se ha descifrado tan frecuentemente el poder en los términos puramente negativos de la ley de prohibición?, ¿Por qué la reflexión sobre el poder se hace inmediatamente como sistema de Derecho?, ¿Por qué

5 En Del buen uso del criminal Foucault nos presenta una crítica demoledora al sistema penal. La pereza de los jueces, la policía, los abogados y los siquiatras condenaron a muerte al joven inocente que no cometió ningún crimen, simplemente porque confesó su acto, pero las pruebas y los hechos nunca coincidían. 
se acepta fácilmente esta concepción jurídica del poder, y por consiguiente la elisión de todo lo que podría construir su eficacia productiva, la riqueza estratégica, su positividad? (Foucault, 1978: 104), y según el filósofo la respuesta está en que el poder solo es tolerable a condición de enmascarar una parte importante de sí mismo, su éxito está en proporción directa con la forma como logra esconder de sus mecanismos (Foucault, 1978: 105). Por tanto, se puede afirmar que el Derecho fue la máscara del poder, porque el Derecho no fue simplemente un arma manejada hábilmente por los monarcas sino la forma general de aceptabilidad del sistema monárquico ${ }^{6}$. En otras palabras, el Derecho como instrumento de poder permitió, además de fijar la soberanía, fijar la dominación, la obediencia y la sujeción de los sujetos. El Derecho no fue entonces simplemente un arma manejada hábilmente por los monarcas; fue el modo de manifestación y la forma de aceptabilidad del sistema monárquico.

Todo lo anterior nos lleva a postular que el objeto de la soberanía no es la vida cualificada del ciudadano, charlatana y protegida por derechos, sino la ruptura de un sujeto sin derechos, de una ley arbitraria y de un poder ilegítimo sobre la vida nuda. Como vemos, no hay arte de gobierno, es decir, un gobernante que maneja las conductas de sus gobernados, sino un poder absoluto, arbitrario y despótico, que se sirve del Derecho para lograr la aceptabilidad del sistema monárquico. Es de anotar que en este régimen los súbditos solo tenían deberes, obligaciones y no derechos, el único que tenía derechos era el monarca. Frente a este asunto Hobbes (1983) nos dice:

6 Para fundamentar su hipótesis de que la política es la guerra continuada por medios sangrientos y violentos, Foucault se remite a los trabajos de los ingleses Eduard Coke y John Lilburne y de los franceses Boulanvillers y Fréret, o el conde D'Estaing. Los ingleses le permiten analizar la historia de Inglaterra desde el inicio de las grandes pugnas religiosas del siglo VII hasta llegar a la misma Revolución Inglesa. Se trata de un discurso de un pequeño grupo político burgués apoyado por los movimientos populares contra la monarquía absoluta. Los franceses cuentan con la aristocracia decadente francesa que pedía derechos y privilegios, avasallados por el ascenso de la monarquía absoluta. Pues bien, es de anotar que la autoridad y el derecho de los reyes franceses procederían en realidad de una apropiación del derecho de conquista por los aristócratas francos, invasores de la Galia Romana, y usurpado por la traición del propio rey al aliarse con los galos vencidos; alianza sellada con la simbólica conversión de Clodoveo al cristianismo. Del discurso inglés se puede afirmar que la soberanía y las leyes descansarían en una usurpación realizada por los normados de Guillermo El Conquistador tras la batalla de Hastings, después de la victoria de los sajones. Cf. (Cerón, 2009 : 93) 
el derecho de ser juez, de castigar y recompensar, de elegir quién vive y quién muere, de decir lo que es bueno o malo, justo o injusto, legítimo e ilegítimo, de hacer la paz y la guerra cuando sea más conveniente.

En resumen, en el antiguo sistema político de la soberanía había entre el soberano y el súbdito toda una serie de relaciones jurídicas y económicas que comprometían y hasta obligaban al primero a proteger al segundo. Pero, en cierto sentido, esa protección era exterior. El súbdito podía pedir a su soberano que lo protegiera contra el enemigo interno.

Para ello el soberano, aplica la fórmula: sancionar una ley y fijar un castigo a quien la infrinja; se trata, entonces, de una acción prohibida y un tipo de castigo.

\section{Biopolítica liberal: "Hacer vivir", "Dejar morir"}

¿En qué consiste, pues, el nuevo poder que permite dar vida en lugar de quitarla?, ¿Por qué en nuestra democracia el valor de la vida está por encima de todas las cosas?, ¿Por qué el liberalismo es la técnica gubernamental por excelencia para conducir a los individuos? Para responder a interrogantes, bien vale la pena recordar nuestra tesis: si el artista en el Medioevo era el soberano, cuya función era la de hacer morir y dejar vivir, el poder en las sociedades capitalistas liberales es un "poder de hacer vivir y dejar morir", un poder de la norma y de la vida que tiene como objetivo el prolongamiento y la maximización de la vida biológica y de la salud de la nación. Para Foucault, ese poder sobre la vida se desarrolló desde el siglo XVII bajo dos formas principales: la primera en constituirse, fue centrándose en el cuerpo como máquina: su educación, el aumento de sus aptitudes, el arrancamiento de sus fuerzas, el crecimiento paralelo de su utilidad y su docilidad, su integración en sistemas de control eficaces y económicos, todo ello quedó asegurado por procedimientos de poder característicos de las disciplinas? : anatomopolítica del

7 La disciplina es una técnica del ejercicio del poder que no fue, propiamente hablando, inventada, sino más bien elaborada durante el siglo XVIII. De hecho, ya había existido a lo largo de la historia, por ejemplo, en la Edad Media, e incluso en la Antigüedad. Al respecto, los monasterios constituyeron un ejemplo de lugar de dominio en cuyo seno reinaba un sistema disciplinario. La esclavitud y las grandes compañías esclavistas existentes en las colonias españolas, inglesas, francesas, holandesas, etcétera, eran también modelos de 
cuerpo humano ${ }^{8}$. La segunda, plasmada algo más tarde, hacia mediados del siglo XVIII, se centró en el cuerpo-especie, en el cuerpo transido por la mecánica de lo viviente y que sirve de soporte a los procesos biológicos: la proliferación, los nacimientos y la mortalidad, el nivel de salud, la duración de la vida y la longevidad, con todas las condiciones que pueden hacerlos variar; todos esos problemas los toman a su cargo una serie de intervenciones y controles reguladores: una Biopolítica de la población.

Así pues, la Biopolítica se basa en el gobierno de una población de la que extrae los mayores beneficios tanto como políticos como económicos, y en la dirección de la conciencia de los individuos para que comprendan las ventajas de esa administración. Dicho de otra manera, la Biopolítica se esfuerza tanto por incrementar la productividad de los sujetos como la aceptación de los principios que sostienen el gobierno. De hecho, es una forma de racionalidad que confía en que al potenciar la vida, más sus capacidades que su número, se pueden desarrollar las facultades de conocimiento (ciencia) y poder (tecnologías). En palabras de nuestro autor:

La Biopolítica decimonónica estaba al servicio de las clases burguesas

-las cuales presentaban una serie de nuevos valores: salud, higiene, vitalidad, prole, en concurrencia con la sangre y el linaje aristocráticoy de la formación de los Estados Nacionales. (Foucault, 2007:117)

Para sostener que es en el siglo XVIII donde se produce un poder no represivo, sino productivo; no un poder conservador sino transformador e innovador; no un poder que atenta contra la vida sino que la potencia, Foucault nos pone el caso de los leprosos y los apestados: a los primeros se los excluye hasta dejarlos morir, a los segundos se los cura para tener cuerpos sanos, disciplinados y productivos para el sistema. Pero dejemos que el mismo autor nos lo cuente:

mecanismos disciplinarios. Podríamos remontarnos a la legión romana y en ella también encontraríamos un ejemplo de disciplina. Cf. (Foucault, 1999:103)

8 La obra de George Orwell 1984, también hace referencia al tema. "Lo que verdaderamente les importa a ellos es el control técnico de las conductas individuales, y en último extremo el de la naturaleza humana." (1970: 7) 
En el fondo, el reemplazo del modelo de la lepra por el modelo de la peste corresponde a un proceso histórico muy importante que, en una palabra, yo llamaría la invención de las tecnologías positivas de poder. La reacción a la lepra es una reacción negativa; una reacción de rechazo, exclusión, etcétera. La reacción a la peste es una reacción positiva; una reacción de inclusión, observación, formación de saber, multiplicación de los efectos de poder a partir de la acumulación de la observación y el saber. Pasamos de una tecnología del poder que expulsa, excluye, prohíbe, margina, y reprime, a un poder que es por fin un poder positivo, un poder que fabrica, que observa, un poder que sabe y se multiplica a partir de sus propios efectos. (Foucault, 2001:55)

Es de recordarque la lepra en las sociedades medieval y antigua se la asociabaconelcastigoporlospecados, alos afectados selos aislabadelasciudades. El Levítico habla de tsara'ath, término traducible como lepra e impone que "todo el tiempo que (el contaminado) estuviere leproso e inmundo habitará solo fuera del poblado"; a lo que sigue todo un conjunto de severas prescripciones de purificación tanto para el afectado como para los vestidos y las casas ${ }^{9}$. Mientras que la lepra había hecho soñar con la sociedad pura, la peste despertaba otro tipo de pesadilla, la que llevaba hacia la sociedad disciplinada. Realmente, es para ponerse a soñar, la ciudad apestada, toda ella atravesada de jerarquía, de vigilancia, de inspección, de escritura, de ciudad inmovilizada en el funcionamiento de un poder extensivo. ¿Cómo se apren-

9 En el Nuevo Testamento, la solicitud del leproso a Jesús para que lo limpie y que éste atiende, va acompañada de la recomendación de cumplir los antiguos preceptos: acudir al sacerdote con las correspondientes ofrendas tal y como se había ordenado desde tiempos de Moisés. La curación prodigiosa de la lepra, como la de cualquier enfermedad, empieza a convertirse en símil de la limpieza misma del pecado. Se pensaba que en los tiempos mesiánicos la lepra desaparecería, con lo que las curaciones de leprosos hechas por Jesús se consideran como un anticipo del tiempo de la salvación. Conviene recordar también lo que la medicina clásica dijo al respecto y cómo lo transmitió al Medioevo. Galeno, sistematizador del corpus hipocrático, dice que la lepra es frecuente en Alejandría a causa del calor y de unas costumbres alimentarias con exceso de productos melancólicos, con abundancia de bilis negra. San Isidoro incluye en un mismo apartado, y dentro de las enfermedades de la piel, la sarna y la lepra. De ésta dice que es "una aspereza escamosa de la piel, semejante a la lepidaberba (hierba fina) de donde toma su nombre. Su color se vuelve ora negruzco, ora rojizo. En el cuerpo humano se detecta la lepra si el color se presenta distinto al de otras zonas sanas de la piel o si se extiende de manera que todo se muestra del mismo color extraño". Cf. (La lepra en el medioevo, 2010). 
dió a luchar contra la peste? Dividiendo el espacio, aislando a los apestados, inspeccionándolos constantemente, practicando permanentes registros. Así se aprendió a luchar contra la peste y esto es lo que se aprendió con ella.

A fin de cuentas, desde el siglo XVIII, los países europeos buscaban individuos productivos en el mercado, que asegurasen el enriquecimiento recíproco, correlativo, más o menos simultáneo de todos los Estados de Europa. El enriquecimiento de Europa se alcanza no gracias a la pobreza de unos y la riqueza de otros, sino por un enriquecimiento colectivo, de tal modo que ningún Estado podía imponerse sobre el otro, evitando así, el imperio $^{10}$. El intercambio de productos permitió el equilibrio entre los países de Europa. En el proyecto kantiano de paz perpetua, que data de 1795, en los momentos finales del siglo XVIII, encontramos un capítulo que se titula "La garantía de la paz perpetua" (Kant, 2004: 267) en el que el filósofo es muy claro en afirmar que la paz no viene de la buena voluntad de los hombres ni tampoco de las alianzas políticas y diplomáticas entre Estados. Lo que garantizaba la paz es la buena regulación del mercado o el intercambio de productos entre los países. Dejemos que el mismo pensador de Königsberg nos lo relate:

Las disposiciones provisionales de la Naturaleza consisten: primera: ella ha cuidado de que los hombres puedan vivir en todas partes del mundo; segunda: los ha distribuido, por medio de la guerra, en todas las comarcas, aun las más inhospitalarias, para que las pueblen y habiten; y tercera: por medio de la guerra misma ha obligado a los hombres a entrar en relaciones mutuas más o menos legales. [...] El espíritu comercial, incompatible con la guerra, se apodera tarde o temprano de los pueblos. De todos los poderes subordinados a la fuerza del Estado, es el poder del dinero el que inspira más confianza, y por eso los Estados se ven obligados no ciertamente por motivos morales a fomentar la paz, y cuando la guerra inminente

10 La policía permitió conservar el equilibrio europeo entre los Estados, sin embargo con la aparición de Napoleón Bonaparte (1769-1821), a través de sus conquistas, sus campañas bélicas, sus agresiones militares a los países vecinos como Italia, donde logró asesinar a millones de seres humanos, impuso el desequilibrio europeo. Más aún: acabó con los estados modernos papales o, como diría Foucault, Napoleón es el punto de ruptura entre la vieja organización del Estado de Policía del siglo XVII y las formas del Estado moderno, que él inventó”. Cf. (Cerón, 2007: 111). 
amenaza el mundo, procuran evitarla con arreglos y componendas, como si estuviesen en constante alianza para ese fin pacífico. (Kant, 2004: 267, 268)

Después de analizar cómo el soberano en el Antiguo Régimen es el artista de la vida de los súbditos y cómo el liberalismo normalizó y sometió al sujeto a la producción capitalista, proponemos ahora la ética como un arte de vida. La estilística de la existencia nada tiene que ver con las normas, sino con las formas que el individuo es capaz de dar a su propia vida.

La vida como inversión, arte y cuidado de sí

Ni el pintor ni el escultor expresan la idea de hombre; creerlo es una imaginación y una ilusión de los sentidos: es la tiranía de los ojos la que nos domina cuando nos expresamos de tal manera, porque los ojos solo ven del cuerpo humano la superficie, la piel; el interior del cuerpo pertenece a la vida

Nietzsche, 2000:1595

El arte de vivir que se propone no está ligado a las técnicas de dominación del soberano o de las instituciones del Estado anteriormente citadas, sino a las técnicas de sí, aquellas que permiten todos los días fabricarnos a nosotros mismos. Estas técnicas, claro está, no apuntan a preguntarse ¿Qué es el hombre? Muchos filósofos dieron ya la respuesta; por ejemplo: el hombre es un animal político, diría Aristóteles; un bípedo implume, afirma graciosamente Platón; un animal razonable, pensaban los estoicos y después los escolásticos; un ser creado, como diría Tomás de Aquino; un ser que ríe (Rabelais); que piensa (Descartes); que juzga (Kant); que trabaja (Marx); que crea (Bergson); un ser dominado y atado por el saber-poder (Foucault). Nuestra pregunta guía: ¿Qué se puede esperar del hombre?, ¿Cómo hacer de su vida una obra de arte? Parafraseando a Kant se diría: lo que puede, debe y espera de sí mismo. Así, pues, el arte de vivir no está ligado al sometimiento a la norma, a la disciplina y al control sino a la actitud de los individuos. 
Surgen, entonces, preguntas: ¿Cómo conducir nuestra vida?, ¿Qué elementos se requieren para que sea obra de arte? Para responder a tan complejos interrogantes nos atrevemos a proponer la siguiente tesis: la salud, la buena prosperidad económica y la felicidad dependerán de la inversión que se haga en las personas. La lógica del capitalismo es la lógica de la ganancia. Bien sabemos que el capital físico o financiero en nuestro medio es importante, pero el capital humano o la inversión en las personas es la clave del progreso de la humanidad. En este mismo sentido comenta Becker Gary, premio Nobel de Economía:

Se han realizado estudios que muestran que si se trata de explicar el crecimiento económico de las distintas naciones del mundo, es esta inversión en capital humano la que se manifiesta como el primer factor que contribuye a explicarlo. Incluso los países que comenzaron en situaciones de pobreza las décadas de los setenta y los ochenta pero que invirtieron grandes cantidades en su gente, muestran unas tasas de crecimiento mucho más rápidas que otros países parecidos que no hicieron ésta inversión en el capital humano. (2002: 24)

Esta sencilla observación nos indica que se deben invertir sumas considerables en las personas, no solo durante su educación escolar por medio de la escuela y no únicamente al comienzo de su vida laboral, sino a lo largo de sus vidas, ya que el conocimiento es un valor que se desprecia. Pero para ilustrar mejor lo comentado supongamos que un profesional en informática formado hace más de diez años, cuando lo único que se enseñaba era programación en D.O.S o Windows 97, hoy en día no sería capaz de desempeñar su carrera adecuadamente a menos que pusiera al día sus conocimientos mediante una educación continua. Esta reflexión nos lleva a plantear que las inversiones tienden a descender con la edad de los individuos, ya que cuanto más elevada sea ésta, menos años quedan para recibir los rendimientos anuales; además los cortes tienden a ser menores cuanto más joven sea el individuo, porque el valor de individuo asignado a la inversión es menor cuando es joven que la cuantía del capital humano a una determinada edad.

Mejor dicho, nuestra reflexión no se orienta hacia el tema del hombre que habita el mundo y reside con sus derechos y deberes en el Estado Social de Derecho, sino hacia el tema de las inversiones en sí mismo. El rendimiento económico de los hogares dependerá de la crianza y educación 
que reciban los hijos. Si aceptamos que el elemento distintivo y diferencial en esta época es la inversión en las personas, porque todo lo demás se puede comprar o copiar ¿Por qué las organizaciones no invierten en potenciar el recurso humano?, ¿Por qué en una crisis económica lo primero que se hace es desvincular personas en vez de buscar el lado positivo a la crisis?, ¿Por qué nuestros países del Tercer Mundo no invierten en el capital humano?

Ahora bien, el artista de sí, vive para sí mismo, dirige una investigación hacia sí mismo, elabora una visión del mundo no teóricamente válida, sino tal que haga la vida cada vez más digna de ser vivida y cada vez más intensa. Para ello se necesita, en primer lugar, una formación profesional que los padres puedan ofrecer al niño y se refiere al tiempo que los padres consagran a sus hijos, al margen de las simples actividades escolares propiamente dichas. Se sabe perfectamente que la cantidad de horas pasadas por una madre junto a su hijo, cuando éste aún está en la cuna, serán muy importantes para la constitución de un capital humano elevado, y que el niño tendrá mucha más capacidad de adaptación si, en efecto, sus padres le han dedicado un tiempo de crianza significativo.

La anterior simplificación nos lleva a postular la ética del artista de sí, que no es normativa, institucional ni racional, sino individual y particular; invita a los individuos a construirse y transformarse a sí mismos, mediante prácticas cotidianas que ellos mismos tienen que inventar para resistir a la dominación y para practicar la libertad. O mejor, para inventarse a sí mismos.

\section{La ética del artista de sí: todo un ejercicio cotidiano}

La ética del artista de sí a la cual nos queremos referir es aquella que intenta crear desde modos de subjetivación, es decir, nuevas formas de habitar el mundo, más allá de la forma y la sustancia, de la práctica y la teoría. Esta ética cuestiona y transforma al sujeto en algo distinto. Como diría Foucault:

Ante todo, una invitación a cuestionar la categoría del sujeto, su supremacía, su función fundadora. Luego, la convicción de que tal operación no tendría ningún sentido si permaneciese limitada a las especulaciones; cuestionar el sujeto significaba experimentar algo que conduciría a su destrucción real, a su disociación, a su explotación, a su conversión en algo muy distinto. (1976: 867) 
De eso se sigue que la práctica de sí, de aquellas éticas grecolatinas que se conocieron con el nombre de epiméleiaheautoü (griego) o cura sui (latín), que traducen "cuidado de sí mismo", no sean un simple ideal filosófico sino una práctica cotidiana concreta para cuidar de sí (ética); cuidar de otros (política); cuidar de las cosas (ciencia). En efecto, el sujeto que cuida de sí invita a construir nuestra propia identidad, a cimentar nuevos valores que guíen nuestra vida, a ser más libres de lo que logramos imaginar, sin necesidad de un fundamento exterior que nos imponga cómo debemos actuar, pensar y obrar. De esta manera, nuestra vida es una obra de arte que brilla y resplandece por sí misma sin que nadie le atribuya una categoría ajena. Al respecto, en La gaya ciencia, Nietzsche comenta: "Pero nosotros queremos ser lo que somos: los hombres únicos incomparables, los que se dan leyes a sí mismos, los que se crean a sí mismos". (Nietzsche, 1949: 335)

Visto así, el artista de sí debe problematizar los pequeños problemas, interrogar las evidencias y los postulados, examinar los hábitos, las maneras de pensar y de actuar del común de la gente y, por qué no, de lo que no es común para la misma gente. Entonces, lo que el artista de sí debe hacer es un croquis topográfico y genealógico para luchar contra las formas del poder, allí donde éste es a la vez el objeto y el instrumento del saber, de la verdad, de la conciencia y del discurso. Es en estos escenarios cotidianos - la familia, la universidad, la fábrica, la cárcel— donde se deben dar las resistencias, de diferentes maneras, ya sea según la estrategia del adversario o el blanco del poder. Por tanto, la resistencia debe ser móvil, cambiante, violenta, lenta, frontal, oscura, activa.

Las formas de resistencia son variables: pueden ser orgánicas o espontáneas, pacíficas o violentas, permanentes o esporádicas, colectivas o individuales. Pero siempre, las resistencias suceden como respuestas específicas a los micropoderes, los cuales existen interrelacionados en el marco más amplio constituido por el campo estratégico del poder. (2000: 41)

Para ilustrar lo dicho anteriormente, supongamos que el mundo capitalista impone los parámetros de la moda: lo extravagante, lo estrafalario, el cuerpo a la carta: aumento o disminución, cambio que se adecúe al paradigma que les permitirá ser más aceptados en la sociedad o sentirse mejor consigo mismo (Porfirio, 2009: 122). Es en estos escenarios dónde el artista 
de sí mismo debe plantearse la resistencia a través de la deliberación, el juzgamiento y la decisión acertada. ¿Cuántas operaciones estéticas mal hechas han frustrado a las personas?

Es necesario aclarar que el artista de sí no está vinculado al sistema jurídico e institucional que lo rodea, determina y articula el universo de los discursos, no se ejerce uniformemente, no se define por los actos que realiza, y no se remite pura y simplemente a la labor social, sino a repensar su papel y desde allí ser un transformador novedoso de subjetividades. Su tarea, en una palabra, será la elaboración crítica de sí mismo, que implica fugas de resistencia a los juegos de verdad y poder.

A causa de ello el artista de sí no debe seguir planteando las preguntas concernientes a solucionar los problemas, en el sentido de decir "Ésta es la única solución", pues su función será la de replantear con el máximo rigor posible los problemas, adentrarse en ellos, hacerlos visibles para la conciencia social, no para su egoísmo, debe demostrarlos y mostrarlos en una complejidad clara que logre callar a los profetas, legisladores y consejeros, a todos los que hablan por los otros, en nombre de los otros ${ }^{11}$. No se trata entonces de encontrar soluciones sino también de provocar dudas e incertidumbres con principios estables.

El artista de sí debe lograr una armonía entre el mundo de la vida y el mundo de las ideas (muy cercano al académico). Contrario a esta tesis, hay sujetos que afirman conocer la verdad y por ello la imponen, mientras que en su vida son personas desequilibradas, injustas, muchas veces déspotas, y en todo momento egoístas. No se equivocaba Ezequiel, al afirmar que los pastores que enseñan la buena doctrina, pero dan mal ejemplo, son un poco

11 La tarea del intelectual comprendía tres funciones: profetizar, legislar y aconsejar, y la realizaba según la función correspondiente. La tarea del intelectual profeta que se atestigua en el Antiguo Testamento era la de anunciar la promesa del Reino y denunciar las injusticias que se cometían, ya no en el paraíso sino en la tierra. [...] Hacer las leyes para guiar a los hombres era el encargo del filósofo intelectual romano. Tal fue el caso de Cicerón (106-43 a. C), quien defendió la idea de la existencia de una ley natural de característica universal y eterna que gobernara la vida de los hombres y de los pueblos en todas las épocas. [...] Finalmente, la función del filósofo griego fue la de aconsejar en el Ágora el mejor gobierno de la polis bajo los tres principios que son: parresía (decir verdad), isegoría (igual derecho a hablar) e isonomía (igual participación en el poder). En consecuencia, Platón comprendió que únicamente la filosofía podría tener éxito en el nuevo nacimiento del Estado, porque el filósofo era el único ser capaz de dar razones y argumentos definitivos para organizar una república justa y feliz. Cf. (Cerón, 2006, pp.240-242) 
como ovejeros que bebieron agua clara, pero, debido a sus pies sucios, corrompieron el agua que hacen beber a las ovejas a su cargo ${ }^{12}$.

Es de anotar que Foucault se opone abiertamente a la idea de un ser humano racional, universal, trascendental, fundante e incondicionado por la modernidad, y a partir del cuidado de sí (epiméleiaheautoú) propone nuevas formas de producir subjetividades ${ }^{13}$, por las cuales los individuos hacen de su vida algo distinto, otra forma de vida, de un estilo nuevo, esto es: la manera de constituirnos como sujetos autónomos para hacer de la vida un proyecto ético-estético ${ }^{14}$. Esto supone elaborar nuevas maneras de existencia donde la libertad des-sujete al individuo de la construcción institucional y de la conciencia constituida por el "gobierno de los otros". Pero dejemos que el mismo autor nos lo cuente:

Lo que me sorprende es que, en la ética griega, la gente se preocupaba más de su conducta moral, de su ética y de la relación para consigo mismo y con los otros que de los problemas religiosos ¿En qué nos convertimos tras la muerte?, ¿Qué son los dioses?, ¿Intervienen

1218 ¿Así que no les basta con pastar en un buen potrero?, ¿Por qué han pisoteado el resto del pasto? Si toman agua clara, ¿por qué han enturbiado el resto con sus pies? 19 ¿Acaso mis ovejas tienen que ramonear lo que ustedes pisotearon, y tomar lo que enturbiaron los pies de ustedes? 20 Por eso, esto dice Yavé: juzgaré tanto las ovejas gordas como a las flacas. Cf. (La biblia, 1995. p. 851)

13 En el año 1979 Foucault revela en el texto El sujeto y el poder, que su trabajo por más de veinte años se ha centrado en plantear una ontología de nosotros mismos, lo cual presupone indagar las condiciones de constitución del sujeto en ámbitos y regímenes diversos. Así lo expresa: "Mi objeto, por el contrario, ha consistido en crear una historia de los diferentes modos de subjetivación del ser humano en nuestra cultura". Sin embargo, la cuestión del poder es uno de los temas centrales del pensamiento de Foucault. Ya desde La historia de la locura en la época clásica se puede detallar su preocupación por los asuntos del poder. Esto no quiere decir que el pensamiento foucaultiano sea contradictorio, o que existan dos Foucault, el del sujeto y el del poder sino, como él afirma: "Más de uno, como yo sin duda, escribe para perder el rostro. No me pregunten quién soy, ni me pidan que permanezca invariable: es una moral de estado civil la que rige nuestra documentación: que nos dejen en paz cuando se trata de escribir." Cf. (Foucault, 1972: 11)

14 Foucault ve en los griegos prácticas individuales que permiten hacer del sujeto algo distinto y nuevo. Con esto no se quiere decir que los griegos sean la solución a nuestros problemas, sino que permiten buscar espacios de libertad. "Intentar volver a pensar hoy a los griegos no consiste en hacer valer la moral griega como el ámbito moral por excelencia del que se tuviera necesidad para pensarse, sino en proceder de tal manera que el pensamiento europeo pudiera arrancar de nuevo en el pensamiento griego como experiencia dada, a la vez y ante la cual se puede ser totalmente libre." Cf. (Foucault, 1997:50) 
o no? Estas cuestiones tenían escasa importancia pues no estaban directamente ligadas a la ética. Ésta a su vez no estaba ligada a un sistema legal. Por ejemplo, las leyes contra la mala conducta sexual no eran numerosas ni muy contradictorias. Lo que interesaba a los griegos, su tema, era la constitución de una ética que fuese una estética de la existencia.

Pues bien, me pregunto si nuestro problema de hoy no es similar de cierto modo, si tenemos en cuenta que la mayoría de nosotros no creemos ya que la ética esté fundada sobre la religión ni queremos un sistema legal que intervenga en nuestra vida privada, moral y personal. Los recientes movimientos de liberación sufren por el hecho de que no consiguen encontrar un principio sobre el cual fundar la elaboración de una nueva ética. Tienen necesidad de una ética pero no encuentran más que una, basada sobre un pretendido conocimiento científico de lo que es el yo, el deseo, el inconsciente.

— ¿Piensaquelos griegosofrecenunaalternativaatrayenteyplausible? ¡No! No busco una solución de relevo; no se encuentra la solución de un problema en algo que ha sido propuesto en otros tiempos para otras gentes. Lo que yo quiero hacer no es la historia de las soluciones y por esta razón no acepto el término "alternativo"; quería hacer la genealogía de los problemas, de las problemáticas. Yo pienso que la opción ético-política que cada día debemos hacer consiste en determinar cuál es el peligro principal. (Foucault, 1994:185)

La ética se contrapone a la sujeción y a la norma, en tanto supone una liberación individual de no estar atado a las formas de domesticación y dominación. Dicho de otro modo, mientras los códigos y leyes sean el centro de nuestra vida, nuestra manera de proceder será hipócrita, injusta y aburrida; en cambio, si obramos a partir de un éthos (ética) se puede darle a nuestra existencia la mejor belleza posible. Más aún: los códigos, las prohibiciones y las normas son un peso más en nuestra vida, puesto que son impuestos. La relación consigo mismo es trabajo personal, en tanto saca tiempo para hacer de la vida una estética de la existencia. Digámoslo con Foucault: 
Historia de las moralidades: aquella que estudia en qué medida las acciones de tales o cuales individuos o grupos se conforman o no con las reglas o con los valores que han sido propuestos por diferentes instancias. Historia de los códigos: la que analiza los diferentes sistemas de reglas y valores que están en juego en una sociedad o un grupo dados, las instancias o aparatos de construcción que le dan valor y las formas que toman su multiplicidad, sus divergencias o sus contradicciones. Historia, en fin, de la manera en que los individuos son llamados a construirse como sujetos de conducta moral: esta historia será la de los modelos propuestos por la instauración y el desenvolvimiento de las relaciones consigo mismo, por la reflexión sobre sí mismo, el conocimiento, el examen, el desciframiento de sí por sí mismo, las transformaciones que se buscan sobre uno mismo. Tal es la que podríamos llamar una historia de la ética y de la ascética, entendida como una historia de las formas de la subjetivación moral y de las prácticas de sí que están destinadas a asegurarlas. (Foucault, 1986: 29, 30)

Esas reflexiones de la Antigüedad grecorromana no se orientaron hacia las codificaciones de conducta, ni tampoco hacia las definiciones en sentido estricto de lo prohibido o lo permitido, sino que fijaron su atención en las prácticas de sí y la cuestión de la askesis. El hecho de que se respetara la ley y las costumbres era condición necesaria, pero lo más importante radicaba en la actitud que obligaba a respetarlas, ya que lo principal era lo siguiente:

El acento se coloca sobre la relación consigo mismo que permite no dejarse llevar por los apetitos y los placeres, conservar respecto de ello dominio y superioridad, mantener los sentidos en un estado de tranquilidad, permanecer libre de toda esclavitud interior respecto de las posiciones y alcanzar un modo de ser que pueda definirse por el pleno disfrute de sí mismo o la perfecta soberanía de sí sobre sí mismo. (Foucault, 1986: 31)

Por eso se puede decir que la templanza en la Antigüedad era una categoría que exigía el triple dominio de los placeres del vino (el potoi), del amor (aphrodisia) y de la mesa (edodai), que a su vez remitía a la prudencia, a la reflexión, al cálculo, consideradas como formas en que se distribuyen y 
controlan los actos: estrategias de lo necesario, la oportunidad, así como del estatuto del individuo, si es adulto o joven; además, éstas eran maneras de proceder para los individuos libres. Para los griegos el enunciado "cuando es debido" (kairos) es tenido en cuenta no solo como el problema moral sino como una cuestión de ciencia y técnica representada en prácticas como la medicina, el gobierno, el pilotaje referido a individuos expertos en la navegación. Entonces se plantean: ¿Es éticamente lícito, desde el kairos como momento oportuno, robar, cometer adulterio, hacer sacrilegios, así nada de ellos atente contra la vida humana?

La virtud de la prudencia fijaba su atención en "la política en el momento", de la ciudad o del individuo, del cuerpo o del alma. La templanza se presenta entre las cualidades que pertenecen a los que tienen rango, posición, responsabilidad y manejo de la ciudad. La categoría de la templanza no se consideraba a partir de un texto que hiciera ley, sino como una techné, es decir, como una práctica, como una habilidad. Así el individuo se constituía como un sujeto ético mediante una actitud y una búsqueda que individualizaba su acción.

A la pregunta ¿Cómo debemos vivir? Foucault jamás dio una respuesta única, válida para todos, ni mucho menos una homogenización en la búsqueda de estilos de existencia. Esta tesis es muy diferente a la propuesta kantiana que obliga a través de los imperativos categóricos ${ }^{15}$, a comportarnos de acuerdo con nuestros deberes y normas válidas para todos. En su última entrevista con Barbedette "El retorno de la moral" nuestro autor, insiste en que la ética es una elección personal y no un deber ser para todos.

Ante todo, la moral antigua se dirigía no más que a un pequeño número de individuos y no pedía que todo el mundo obedeciera al mismo esquema de comportamiento. No concernía más que a una minoría de entre todos, e incluso entre los libres. Había varias formas de libertad: la libertad del jefe de Estado o del jefe del ejército no tenía nada que ver con la del sabio. Después, esta moral se extendió. En la época de Séneca, y con más razón en la de Marco Aurelio; debía valer; eventualmente para todo el mundo; jamás era cuestión de hacer

15 "Obra de tal modo que uses la humanidad, tanto en tu persona como en la persona de cualquier otro, siempre como un fin al mismo tiempo y nunca solamente como un medio." Cf. (Kant, 1973: 94) 
de ella una obligación para todos. Era un asunto de elección para los individuos; cada uno podía llegar a compartir esta moral. (Foucault, 1999: 383)

Hay que repetirlo: la eticidad foucaultiana está asociada a una vida bella por el arte de vivir y gobernarse a sí mismo, por el estilo o invención de uno mismo, pues el sujeto es objeto de su propia invención porque elabora sus propias conductas y por consiguiente su manera de ser en el mundo ${ }^{16}$; contrario a este planteamiento, está el sistema de códigos morales, de normas universales, donde los individuos deben obedecer a una moral determinada; por ejemplo, la moral cristiana del poder pastoral es un modo particular de relación con uno mismo en la que el individuo se ve sujeto a formas precisas de atención, recelo, desciframiento, verbalización, confesión, autoacusación, luchas contra las tentaciones, renuncia y lucha espiritual. Nuestro autor nos ha señalado por lo menos tres formas de asumir la moral:

Moral: Como conjunto de valores y de reglas de acción que se proponen a los individuos y a los grupos por medio de aparatos prescriptivos diversos (familia-Iglesia-escuela). Moral: como el comportamiento real de los individuos en su relación con las reglas y valores que se les proponen. Moral: como la manera en que debe constituirse uno mismo como sujeto moral que actúa en referencia a los elementos prescriptivos que constituyen el código. (Foucault, 1986: 28)

Estas diferencias pueden apoyarse en muchos puntos. La manera como el individuo debe dar forma a tal o cual parte de sí mismo como materia principal de su conducta moral (reglas, deseos, sentimientos).

16 La exterioridad de la moral antigua o pagana implicaba un trabajo sobre uno mismo que era definido en la lengua clásica, enkrateia, forma de relación con uno mismo, actitud necesaria a la moral de los placeres y que se manifestaba en el buen uso que de ella se hacía. Para Aristóteles, esa enkrateia era considerada como un dominio y una victoria, una relación de dominación y de mando. Los términos utilizados por Platón, Jenofonte, Diógenes El cínico, Antifón, y Aristóteles para definir la templanza era: dominar los deseos y los placeres, ejercer el poder sobre ellos, mandar en ellos. De tal manera que, para constituirse como sujetos virtuoso, temperante en el uso que se hace de los placeres, el individuo debe instaurar una relación consigo mismo que pertenece al tipo: dominación-obediencia, mando-sumisión, señorío-docilidad, tipos que formaban parte de la estructura autocrática del sujeto en la práctica moral de los placeres. (Rivera, 2001: 81) 
Conviene también al modo de sujeción, es decir a la forma en que el individuo establece su relación con esta regla y se reconoce como vínculo con la obligación de ponerla en obra (o sea los motivos o razones por los cuales un individuo práctica, por ejemplo, la fidelidad conyugal). La diferencia tiene que ver también con la elaboración del trabajo ético que realizamos en nosotros mismos y no solo para que nuestro comportamiento sea conforme a una regla dada sino para intentar transformarnos nosotros mismos en sujeto moral de nuestra conducta. Veamos:

Una manera de vivir cuyo valor moral no obedece ni a su conformidad con un código de comportamiento ni a un trabajo de purificación, sino a ciertas formas o ciertos principios formales generales en el uso de los placeres, en la distribución que de ellos hacemos, en los límites que observamos, en la jerarquía que respetamos. Por el logos, por la razón y la relación con lo verdadero que la gobierna, una vida así se inscribe en el mantenimiento o la reproducción de un orden ontológico; recibe por otra parte el resplandor de una belleza manifestada a los ojos de quienes pueden contemplar o conservar su recuerdo. (Foucault, 1986: 87)

Otra diferencia concierne a lo que podríamos llamar teología del sujeto moral: ya que una acción no solo es moral en sí misma y en su singularidad, también lo es por su inserción y por el lugar que ocupa en el conjunto de una conducta; es un elemento y un aspecto de esta conducta y señala una etapa en su duración, un progreso eventual en su continuidad. Una acción moral tiende a su propio cumplimiento, pero además intenta, por medio de éste, la constitución de una conducta moral.

Cierto que toda acción moral implica una relación con la realidad en la que se lleva a cabo y una relación con el código al que se refiere, pero también implica una determinada relación consigo mismo; ésta no es simplemente "conciencia de sî", sino constitución de sí como sujeto moral, en la que el individuo circunscribe la parte de sí mismo que constituye el objeto de esta práctica moral, define su posición en relación con el precepto que sigue, se fija un determinado modo de ser que valdrá como cumplimiento moral de sí mismo. Busca conocerse, se controla, se prueba, se perfecciona, se transforma. No hay acción moral particular que no se refiera a una conducta moral; ni conducta 
moral que no reclame la constitución de sí misma como sujeto moral, ni constitución del sujeto moral sin modos de subjetivación y sin una ascética o prácticas de sí que los apoyen. (Foucault, 1986: 30)

Así, pues, la ética foucaultiana es la práctica reflexiva de la libertad porque las técnicas de dominación del saber y el poder, la vigilancia permanente de los panópticos ${ }^{17}$, le han impedido a los sujetos su autonomía; es decir, su libertad; en otras palabras, la libertad es la condición de posibilidad para la ética, sin ésta estaríamos en los instrumentos de sujeción. Así nos los presenta nuestro autor:

Sí, porque ¿Qué es la ética sino la práctica de la libertad, la práctica reflexiva de la libertad [...] La libertad es la condición de posibilidad ontológica de la ética. Pero la ética es la forma reflexiva que adopta la libertad [...] Hay que subrayar también que no puede haber relaciones de poder más que en la medida en que los sujetos son libres. Si uno de los dos estuviera completamente a disposición del otro y llegara a ser una cosa suya, un objeto sobre el que pudiera ejercer una violencia infinita e ilimitada, no habría relaciones de poder. Para que se ejerza una relación de poder hace falta, por tanto, que exista siempre cierta forma de libertad para ambos lados. (Foucault, 1999: 396, 405)

Pues bien, las prácticas de sí permiten la autotransformación del sujeto, la elaboración sobre sí mismo, un modo de ser diferente. En este sentido, la ética o la práctica reflexiva de la libertad, lleva al conocimiento de sí, de los otros y de las cosas. Conocimiento que implica el arte de gobernarse como autarquía y de habitar la ciudad con el mínimo de dominación, advirtiendo siempre los peligros del poder tanto en sus relaciones estratégicas como en sus técnicas y estados de dominación. De ello se deduce que el sujeto que promueve Foucault, es un sujeto ético y estético que está en proceso de darse y moldearse a sí mismo ${ }^{18}$, en oposición a la Filosofía Política

$17 \mathrm{Al}$ igual que Bentham, Foucault sabe que la función básica del panóptico, el ojo del poder, es conseguir que todos los individuos sean útiles, primero a sí mismos y en consecuencia, al conjunto de la sociedad. Es una idea expuesta por Hobbes, y recogida después por Bentham y Stuart Mill. Lo que es bueno para el individuo es bueno para la sociedad.

18 "Félix Guattari señala cómo esta gran transformación comprende varias modificaciones; en primer lugar, las transversalidad de atravesar los límites de un territorio particular donde 
tradicional que ha presentado un sujeto ya dado y establecido sea por la lucha de clases (marxismo) o por el sistema jurídico, un sujeto de derechos y obligaciones ${ }^{19}$. Dejemos que el mismo autor nos lo aclare:

Hace dos o tres siglos la filosofía occidental postulaba, explícita o implícitamente al sujeto como fundamento, como núcleo central de todo conocimiento, como aquello en que no solo se revelaba la libertad sino en que podía hacer eclosión la verdad [...] podemos ver cómo cierta tradición universitaria o académica del marxismo, concepción tradicionalista del sujeto desde el punto de vista filosófico, aún continúa. Esto es, en mi opinión, lo que debe llevarse a cabo: la constitución histórica de un sujeto a través de un discurso tomado como un conjunto de estrategias que forman parte de las prácticas sociales [...] entre las prácticas sociales en las que el análisis histórico permite localizar la emergencia de nuevas formas de subjetividad, las prácticas jurídicas, o más precisamente las prácticas judiciales están entre las más importantes. (Foucault, 1999, 396-405)

Marx exige que el "hombre humano" sea conocido y reconocido. A este hombre lo encuentra él en la sociedad. El hombre social es para él el hombre natural. En la sociedad se asegura uniformemente la naturaleza del hombre, esto es, la totalidad de las demandas naturales (alimentación, vestido, reproducción, suficiencia económica). Contrario a esta teoría social, el individuo que cuida de sí, ética; cuidar de otros, política; cuidar de las cosas, ciencia $^{20}$, logra la transformación de la subjetividad. Por tal motivo,

se constituya la subjetividad como un producto; en segundo lugar, oponerse a todas las categorías producto del poder, las que están relacionadas con la lucha social visible y las que se ejercen sobre el cuerpo y la salud; en tercer lugar, las transformaciones de la subjetividad son inmediatas y concernientes a las más cercanas luchas del poder. No remite a programas de partidos políticos o a futuras e hipotéticas soluciones; en cuarto lugar, tales luchas cuestionan el estatuto del individuo normalizado y afirman un derecho inalienable a la diferencia, compatible con muchas estrategias comunitarias; en quinto lugar, estas trasformaciones de la subjetividad sortean los privilegios del saber y sus funciones mistificadoras. Finalmente, toda revolución de la subjetivación comprende un rechazo de la violencia económica e ideológica del Estado y de todas sus formas de inquisición científica y administrativa. Cf. (Sauquillo, 2001: 174-175)

19 Los sujetos colectivos pueden ser, entre otros, el Estado, la sociedad civil, la nación, las clases, la masa, la familia, el grupo, el partido.

20 Foucault denominó ciencia al cuidado de las cosas; política al cuidado de los otros; y ética al cuidado de sí. En sus palabras tenemos: "Relaciones de dominio sobre las cosas, relacio- 
si practicamos el diálogo entre un buen maestro y un discípulo, buscamos un consejo apropiado, cultivamos una verdadera amistad y nos alejamos de los falsos apegos, logramos hacer de nuestra vida una obra de arte. En este sentido, la ética tal como la hemos presentado, no es solo una forma de atención, de reflexión sobre nuestro diario, sino que es un trabajo de formación del individuo para la vida bella y feliz. La ética es, entonces, medicina para el alma, serenidad y conocimiento práctico de la existencia, perfección del propio yo, pensar y trabajar sobre sí mismo para vivir mejor. En el texto citado Sauquillo comenta:

El souci de soi es privilegio, deber y técnica muy valorada El souci de soi comprende una tarea regulada, dotada de procedimientos y objetivos filosóficos. Foucault ha señalado cómo para Séneca, Plutarco y Epícteto el cuidado o gobierno de sí mismo implica un recogimiento, una forma de habitar en uno y establecer con uno ciertas relaciones. Estas relaciones de recogimiento estoico se conciben de acuerdo al modelo jurídico-político: quien se gobierna es soberano de uno mismo, es plenamente independiente, y ejerce una dirección perfecta sobre él mismo. Además, este género de relaciones encarna una alegría posesiva: goce de la propia individualidad y satisfacción en ella de toda su voluptuosidad. En la Antigüedad esta práctica de la subjetividad artística reunía tres funciones. En primer lugar, comprende una función crítica por la que el sujeto desaprende todas las malas costumbres y las falsas opiniones procedentes del entorno. En segundo lugar, guarda una función de lucha inculcadora de una concepción de la vida como un combate permanente con aquella parte de la exterioridad que le es adversa. En tercer lugar, el cultivo de uno mismo posee una función curativa y terapéutica dirigida a sanar las enfermedades del alma. Estas tres funciones coinciden en dotar al sujeto de un ejercicio de askesis. El sujeto debía comportarse de la misma manera que un atleta: éste no derrocha sus energías con esfuerzos innecesarios o inútiles. El sujeto ascético se ejercita estrictamente en aquellos ejercicios que le son necesarios en la lucha para vencer a sus adversarios. Como el buen luchador, debe ser diestro en aquellos movimientos que le permitan resistir a

nes de acción sobre los otros, relaciones con uno mismo. [...] los ejes del saber, del poder, de la ética." (Foucault, 1999: 347) 
los acontecimientos acaecibles de manera inconmovible. Quien no guarda una relación de askesisse abandona en un estado de akracio. (Sauquillo, 2001: 173)

Foucault nos ha repetido una y otra vez la idea según la cual cada individuo puede constituirse como sujeto moral de sus conductas. Desde esta perspectiva ético-estética o ética de la existencia, la vida se convierte en una terapia o medicina de sí, para evitar la superioridad en la casa, en la escuela, la fábrica o en todos los lugares donde se ejerce el poder como dominación. En otras palabras, cuidamos de sí para no dominar ni tampoco para que nos dominen.

Ahora bien, nos encontramos en un mundo donde esas regulaciones no pueden ya juzgar de la misma manera: la relación de superioridad ejercida en la casa y sobre la esposa debe compaginarse con ciertas formas de reciprocidad y de igualdad [...] De suerte que el principio de la superioridad sobre uno mismo como núcleo ético esencial, la forma general "heautocratismo", está por reestructurarse, no que desaparezca, pero ha de dejar lugar a cierto equilibrio entre desigualdad y reciprocidad en la vida matrimonial y en la vida social, cívica y política, que le es preciso hacer jugar cierta disociación entre el poder sobre sí y el poder sobre los demás. La importancia concebida al problema de "uno mismo", al desarrollo del cultivo de sí en el transcurso del período helenístico y el apogeo que conoció al principio del Imperio manifiesta ese esfuerzo de reelaboración de una ética del dominio de sí. La reflexión sobre el uso de los placeres estaba tan directamente ligada a la estrecha correlación entre los tres dominios (sobre sí mismo, sobre la casa y sobre los demás) que se encontrará modificada en el transcurso mismo de esa elaboración. ¿Crecimiento de las constricciones públicas y de las prohibiciones?, ¿Repliegue individualista que acompañaba a la valoración de la vida privada? Hay que pensar más bien en una crisis del sujeto o más bien de la subjetivación: en una dificultad en la manera en que el individuo puede constituirse como sujeto moral de sus conductas, y en unos esfuerzos por encontrar en la aplicación a sí mismo lo que puede permitirse someterse a unas reglas y dar una finalidad a su existencia. (Foucault, 1997: 93) 
En consecuencia, el artista de sí mismo debe invitar a construir nuestra propia identidad, a cimentar nuevos valores que guíen nuestra vida, a ser más libres de lo que logramos imaginar, sin necesidad de un fundamento exterior que nos imponga cómo debemos actuar, pensar y obrar. De esta manera, nuestra vida es una obra de arte que brilla y resplandece por sí misma sin que nadie le atribuya una categoría ajena. Remato este escrito con las palabras del profesor Gonzalo Soto:

El cuidado de sí no es solo el autoconocimiento socrático-platónico ni el cogito cartesiano; es un conjunto de prácticas de sí como tecnologías del yo: ritos de purificación, técnicas de concentración, técnicas de retiro (anáchoresis), ejercicios de resistencia, técnicas de meditación, técnicas de memorización del pasado, técnicas de estado de conciencia, técnicas de verificación de las representaciones para toda la vida: todo hombre debe ocupar día y noche y a lo largo de toda su vida de su propia alma. Este proceso siempre en ebullición hace que el yo continuamente se descomponga, se libere, se convierta (anastrophé- epistrophe-conversio), se corrija, se altere, se modifique, cambie constantemente, devenga un facendumen, nunca un factum: es el mismo en el otro y lo otro desde el juego identidad-diferencia gracias a la libertad como ejercicio ético. (Soto, 2009: 570)

\section{CONCLUSIONES}

No se pretende resumir lo que anteriormente se ha dicho sino plantear nuevas preguntas para la fabricación de sí mismo: el artista de sí, ¿con quién tiene que vivir? Me atrevería a decir que como artista debe buscar otra persona con las mejores "constituciones genéticas", es decir buscar un cónyuge con las mismas características físicas, o mejores, para la procreación. De hecho una persona alta, bonita, con unas medidas proporcionales, buscará otra persona con las mismas características físicas, o muy parecidas. Al respecto Foucault comenta:

Para ser más claro, esto querrá decir que, dada mi constitución genética, si deseo tener un descendiente cuya constitución sea por lo menos tan buena como la mía o mejor, en la medida de lo posible, deberé además procurar casarme con alguien cuya constitución genética 
también sea buena. Y supongo que advertirán con toda claridad que el mecanismo de producción de los individuos, producción de niños, puede encontrar toda problemática económica y social a partir de la cuestión de la escasez de buenas constituciones genéticas. Y si uno quiere tener un hijo cuyo capital humano sea elevado, entendido simplemente en términos de elementos innatos y elementos adquiridos, necesitará hacer una completa inversión, vale decir, haber trabajado lo suficiente, tener ingresos suficientes, tener un estatus social tal que le permita tener por cónyuge o coproductor de ese futuro capital humano a alguien cuyo capital propio sea importante. Les digo esto y, en última instancia, no se trata en absoluto de una broma; es simplemente una forma de pensamiento o una problemática que en la actualidad se encuentra en estado de emulsión. (2007: 268)

Continuando con el análisis, podemos postular que la pareja es el compromiso contractual de dos partes de suministrar ingresos específicos y compartir en proporciones dadas los beneficios del gasto del hogar. Entonces, surge preguntarse: ¿Qué sentido tiene el contrato a largo plazo que se celebra entre la gente que vive en pareja y bajo la forma matrimonial?, ¿Cuál es su justificación económica, qué es lo que lo funda? Pues bien, el contrato a largo plazo entre cónyuges permite evitar renegociar a cada instante y sin cesar los innumerables contratos que deberían suscribirse para hacer funcionar la vida doméstica. Citando a Pierre Rivière, Foucault plantea:

Esto puede parecer extraño, pero aquellos de ustedes que conocen el texto dejado por Pierre Rivière antes de su muerte, donde describe cómo vivían sus padres, se darán cuenta de que, en efecto, la vida matrimonial de una pareja de campesinos a principios del siglo XIX estaba permanentemente tejida y tramada por una serie de transacciones. Voy a arar tu campo, dice el hombre a la mujer, pero con la condición de que pueda hacer el amor contigo. Y la mujer dice: No harás el amor conmigo hasta que no hayas alimentado a mis gallinas. En un proceso como éste vemos aparecer una especie de transacción permanente, con respecto a la cual el contrato de matrimonio debía constituir una forma de economía global que evitaba la necesidad de negociar a cada instante. Y en cierto modo, la relación entre el padre y la madre, entre el hombre y la mujer, no era otra 
cosa que el desarrollo cotidiano de esa suerte de contractualización del contrato; pero al mismo éste no cumplía su papel: en los hechos, no había permitido el ahorro del costo de transacción que habría debido garantizar. En síntesis, digamos que en esos análisis económicos de los neoliberales tenemos una tentativa de desciframiento económico de comportamientos sociales tradicionalmente no económicos. (Foucault, 2007: 271)

¿Cuáles son las atenciones medias del artista de sí? Respondemos: la salud de los individuos, el tiempo de la lactancia, los cuidados brindados, el nivel cultural de los padres y el conjunto de los estímulos culturales recibidos por un niño: todo eso va a constituir elementos capaces de formar un capital humano elevado. Frente a este asunto, nuestro pensador afirma:

En el análisis que hacen del capital humano, como recordarán, los neoliberales tratan de explicar, por ejemplo, que la relación madrehijo, caracterizada concretamente por el tiempo que la primera pasa con el segundo, la calidad de los cuidados que le brinda, el afecto que le prodiga, la vigilancia con la que sigue su desarrollo, su educación, no solo sus progresos escolares sino también físicos, no solo su manera de alimentarlo sino también de refinar la alimentación y la relación alimentaria que tiene con él, todo eso representa para ellos, los neoliberales, una inversión, una inversión mensurable en el tiempo. ¿Y qué va a construir esa inversión? Un capital humano, el capital humano del niño, que producirá una renta. ¿Y qué será esa renta? El salario del niño cuando se haya convertido en adulto. Y para la madre, que ha invertido, ¿Cuál será la renta? Pues bien, dicen los neoliberales, una renta psíquica, que consiste en la satisfacción que experimentan al cuidar al niño y ver que esos cuidados han dado frutos. Es posible entonces analizar en términos de inversión, de costo del capital, de ganancia del capital invertido, de ganancia económica y ganancia psicológica, toda esa relación que, si se quiere, puede [llamarse] relación formativa o relación educacional, en el sentido muy amplio de la palabra, entre la madre y el hijo. (Foucault, 2007: 275)

¿Quiénes deben ocuparse de sí mismos? Ya hemos afirmado que para los griegos de la Antigüedad, los jóvenes atenienses tenían que ocuparse de sí, para poder ejercer el poder como es debido, razonable y virtuosamente 
el poder al cual uno está destinado. Sócrates recomienda a Alcibíades conocerse a sí mismo, para conocer a sus enemigos, para ser un buen gobernante y para gobernar con justicia la ciudad. En nuestros días, cuando buscamos un modo apropiado de vida, practicamos la virtud, la prudencia, asumimos nuestra existencia, todos estamos invitados a ocuparnos de nosotros mismos. Tenemos necesidad de ser sujetos de acción capaces de responder con rectitud y firmeza a los sucesos de la vida. Por ejemplo, cuando cumplo mis deberes en la familia y ejerzo un buen gobierno en la casa estoy ocupándome de mí mismo.

Queda entonces preguntarse: ¿Cómo se constituye el sujeto?, ¿Cuál es su relación con la verdad?, ¿Cómo se debe transformar el sujeto para acceder a la verdad?, ¿Cómo interviene el otro en la transformación del sujeto?, ¿Qué no es el cuidado de sí? Será que el goce, la imprudencia, el vicio, los ejercicios en exceso, ¿atentan contra el cuidado de sí? Preguntas para otra reflexión.

\section{REFERENCIAS}

Baudelaire, Ch. (1995). El pintor de la vida moderna. Bogotá: El Áncora Editores.

BeCKeR, G. (2002). La inversión en talento como valor de futuro. En Revista Capital Humano, 153.

Biblia Latinoamericana, La. (1995). Antiguo Testamento, libro del Génesis, 1, 26-28. Madrid: El Verbo Divino.

Cardona, P. (2009). Cosmología, representación y experiencia estética. En Posontología, posmetafísica en el siglo XXI. Medellín: Universidad Pontificia Bolivariana.

Ceballos, H. (2000). Foucault y el poder. México: Coyoacán.

CERÓn, W. (2006). El compromiso de los intelectuales entre lo universal y lo específico. En Escenario de reflexión. Las ciencias sociales y humanas a debate. Medellín: Universidad Nacional de Colombia.

CERón, W. (2007). La filosofía política de Michel Foucault: pensar la política desde el cuidado de sí. Tesis para optar el titulo de Magíster en Estudios Políticos. Medellín: Universidad Pontificia Bolivariana.

Cerón, W. (2009). Foucault, lector de Nietzsche. A propósito de la genealogía y la guerra. En Posontología y posmetafísica en el siglo XXI. Medellín: Universidad Pontificia Bolivariana. 
Foucault, M. (1972). La arqueología del saber. México: Siglo XXI, 1972.

Foucault, M. (1976). Dits et écrits II. Paris: Gallimard.

Foucault, M. (1978). Historia de la sexualidad: La voluntad de saber. Tomo

I. Madrid: Siglo XXI.

Foucault, M. (1983). La verdad y sus formas jurídicas. México: Gedisa

Foucault, M. (1986). Historia de la Sexualidad II. El uso de los placeres.

México: Siglo XXI.

Foucault, M. (1991). Saber y verdad. Madrid: La Piqueta.

Foucault, M. (1992).Genealogía del racismo. Madrid: La Piqueta.

Foucault, M. (1997). Historia de la sexualidad: La inquietud de sí. México:

Siglo XXI.

Foucault, M. (1999).Vigilar y Castigar. Madrid: Siglo XXI.

Foucault, M. (2001). Los anormales. Buenos Aires: Fondo de Cultura Económica.

Foucault, M. (1994). Hermenéutica del sujeto. Madrid: La Piqueta.

Foucault, M. (1999). Estética, ética y hermenéutica. Vol. III. Barcelona: Paidós.

Foucault, M. (2007). Nacimiento de la Biopolítica. Buenos Aires: Fondo de Cultura Económica.

HeidegGer, M. (2009). La voluntad de poder. Disponible en: http://www. nietzscheana.com.ar/textos.htm

Hobbes, T. (1983). Leviatán o La materia, forma y poder de una República Eclesiástica y Civil. Madrid: Fondo de Cultura Económica.

Kant, E. (1973). Fundamentación de la metafísica de las costumbres. Madrid: Espasa.

Kant, E. (2004). La paz perpetua. México D.F.: Porrúa.

La lepra en el medioevo. (2010). Disponible en: http://www.institutojauretche. edu.ar/barajar/octubre/nota8.html

Nietzsche, F. (2000). Así hablaba Zaratustra. Tom. II., Barcelona: Edicomunicación, S.A.

Nietzsche, F. (2000). Humano demasiado humano. Tom. IV, Barcelona: Edicomunicación, S.A.

Nietzsche, F. (1949). La gaya ciencia. Buenos Aires: s.i.

ORwell, G. (1970). 1984. Navarra: Salvat.

RiverA, M. S. (2001). Una aproximación al pensamiento ético-estético de Michel Foucault. Revista de Sociología, 24. 
William Cerón

SAuQuillo, J. (2001). Para leer a Foucault. España: Alianza.

Soto Posada, G. (2009). La Filosofía como forma de vida. En Revista Escritos, (17), 39. 